\title{
CONTRIBUICCÕES DE OFICINAS DE PRODUÇÃO DE RECURSOS DIDÁTICOS NA FORMAÇÃO INICIAL DE PROFESSORES DE QUÍMICA
}

\author{
Cynthia Torres Daher*, Michele Waltz Comarú, Carolina Nascimento Spiegel \\ *E-mail: cynthia.torres.daher@gmail.com \\ Instituto Federal do Espírito Santo, Instituto Federal do Rio de Janeiro, Universidade \\ Federal Fluminense \\ DOI: $10.15628 /$ rbept.2020.9176 \\ Artigo submetido em nov/2019 e aceito em mar/2020
}

\begin{abstract}
RESUMO
Relata experiência de oficinas de produção de recursos didáticos na formação inicial de docentes de Química no Instituto Federal do Espírito Santo como meio de potencializar a formação de professores como intelectuais reflexivos e pesquisadores da própria prática. Descreve intuito de contemplar as práticas como componente curricular por meio do estímulo à autonomia, autoria, criatividade e liberdade dos licenciandos a partir das oito edições já realizadas das oficinas. As experiências vivenciadas apontam favorecimento ao diálogo entre teoria e prática, entre saberes específicos e pedagógicos e entre docentes formadores de diferentes áreas de conhecimento. Apontam ainda desafios na criação de repositório dos recursos didáticos e na correção de erros conceituais identificados em alguns produtos. As abordagens inclusivas e no âmbito dos pressupostos do movimento ciência, tecnologia, sociedade e ambiente são aspectos aprimorados a cada nova edição.
\end{abstract}

Palavras-chave: Recursos didáticos. Formação inicial de professores. Licenciatura em Química.

\section{CONTRIBUTIONS OF PRODUCTION WORKSHOPS OF DIDACTIC RESOURCES IN THE INITIAL BACKGROUND OF CHEMISTRY TEACHERS}

\begin{abstract}
This study reports the experience of production workshops of didactic resources in the initial background of Chemistry teachers at the Instituto Federal do Espírito as a way to strenghten the teachers' background as reflexive intellectuals and researchers of their own practice. It describes the aim of contemplating the practices as a curricular component through the motivation to autonomy, autorship, creativity and freedom of the teachers-to-be from the eight past editions of the workshops. The experiences demonstrate fostering the dialogue between theory and practice, specific and pedagogical knowledge and among professors, who help form knowledge in different areas. These experiences also show challenges in the development of a repository of didactic resources and in the correction of concept errors identified in some products. Inclusive approaches and within the assumptions of science, technology, society and environment movement are aspects improved in every edition.
\end{abstract}

Key words: Didactic resources. Initial teachers' background. Chemistry degree. 


\section{INTRODUÇÃO}

Breve análise de instrumentos oficiais que regem a formação inicial de professores que atuam na Educação Básica no Brasil aponta tentativa de contribuir para melhor articulação entre teoria e prática. Desde 2002 as Resoluções CNE/CP № 01/2002 e CNE/CP № 02/2002 que instituíram as Diretrizes Curriculares Nacionais e a carga horária para formação desses professores em nível superior passaram a reorganizar os currículos dos cursos apontando tentativa de superação do modelo $3+1$ - três anos de formação técnica centrada no conhecimento de conteúdo da área de formação, mais um ano de disciplinas pedagógicas, incluindo as práticas de ensino e o estágio supervisionado.

O novo formato curricular conferia abordagem das dimensões práticas e pedagógicas (NÓVOA, 1999) desde o início do curso. No mesmo viés, a atual Resolução CNE/CP № 02/2015 que institui as Diretrizes Curriculares Nacionais para a formação inicial e continuada em nível superior de profissionais do magistério para a Educação Básica, não alterou essa lógica curricular. Manteve a obrigatoriedade de 400 horas destinadas aos estágios vivenciados a partir da segunda metade dos cursos, 400 horas destinadas à prática como componente curricular vivenciadas ao longo de todo o curso e não menos que a quinta parte da carga horária total dedicada às dimensões pedagógicas.

Ainda em nível oficial, o parágrafo único do Art. 61 da Lei de Diretrizes e Bases da Educação Nacional, LDB 9394/96, aponta a associação entre teorias e práticas como base para formação de profissionais da educação. Fica, assim, explicitado estímulo à práxis na formação inicial. Todavia, embora instrumentos legais atribuam normas, currículos e cargas horárias, não asseguram sua vivência. Nesse sentido, segundo Lopes (2004), as pesquisas sobre políticas de currículo podem ser incluídas em duas vertentes: as que focalizam a esfera oficial, analisando determinantes de ações governamentais e suas orientações político-ideológicas e as que confrontam políticas oficiais com os processos de implantação. No último caso, "seja para questionar as políticas oficiais pelo seu distanciamento da prática, seja para questionar a prática pelo seu distanciamento das políticas" (LOPES, 2004, p. 46).

Em nível de experiência profissional, é sabido que, hoje, 17 anos após aprovação das resoluções supracitadas, ainda não é possível afirmar que o modelo $3+1$ tenha sido de fato superado. Embora por força de lei muitos currículos tenham sido adequados quanto à disposição dos componentes curriculares e, a princípio, pareçam atender demandas de autorização e reconhecimento, na prática, o que se percebe é uma junção de saberes que não dialogam. Não se nega que tal formato representa avanço em relação ao modelo anterior, o percurso de justaposição parece representar uma etapa no 
processo de mudança. Entretanto, novos percursos são necessários e possíveis, de preferência que não desvinculem a formação do conteúdo específico da formação pedagógica (SILVA e COMARÚ, 2017).

Considerando esses desafios, o presente texto tem por objetivo relatar e discutir experiência que buscou reduzir o distanciamento entre teoria e prática e entre saberes específicos e pedagógicos, com vistas a contribuir para a dimensão formativa da prática como componente curricular nos cursos de formação de professores. Trata-se da descrição de ação pedagógica desenvolvida junto a licenciandos em Química do Instituto Federal do Espírito Santo (Ifes) envolvendo a evolução de oficinas de produção de recursos didáticos e seu potencial na formação de professores como intelectuais críticos reflexivos (PIMENTA, 2002) e pesquisadores da própria prática (ESTEBAN e ZACCUR, 2002), mas de que tipo de formação se deseja tratar quando essas expressões são empregadas? Pimenta (2002) evidencia a:

[...] indiscutível contribuição da perspectiva da reflexão no exercício da docência para a valorização da profissão docente, dos saberes dos professores, do trabalho coletivo destes e das escolas enquanto espaço de formação contínua. Isso porque assinala que o professor pode produzir conhecimento a partir da própria prática, desde que a investigação reflita intencionalmente sobre ela, problematizando resultados obtidos com suporte da teoria. E, portanto, como pesquisador de sua própria prática (p. 43).

Todavia, para tal, Pimenta (2002) adverte a necessidade de superação de habituais limitações como: a promoção de reflexão de caráter mais público e ético e menos individualizado; a valorização da práxis por meio da construção de conhecimentos a partir de análise fundamentada da prática e da ressignificação de teorias a partir da prática em detrimento de uma epistemologia exclusivamente da prática.

Assim, a dimensão do uso e, especialmente, da produção de recursos didáticos como mediadores da formação dos docentes pode representar rica possibilidade de contribuir para articular saberes específicos, pedagógicos e da experiência (NÓVOA, 1999). Ao cooperar para integrar teoria e prática, os recursos educacionais podem ainda auxiliar docentes a adotarem postura mais reflexiva e transformadora da realidade, em consonância com proposta de educação pela pesquisa (DEMO, 2015) e assumindo a natureza investigativa da prática docente (FREIRE, 1996):

Fala-se hoje, com insistência, no professor pesquisador. No meu entender o que há de pesquisador no professor não é uma qualidade ou uma forma de ser ou de atuar que se acrescente à de ensinar. Faz parte da natureza da prática docente a indagação, a busca, a pesquisa. $\mathrm{O}$ que se precisa é que, em sua formação permanente, o professor se perceba e se assuma, porque professor, como pesquisador (p. 32). 
Utilizados como instrumentos mediadores da transposição didática de conhecimentos científicos para conhecimentos escolares em diferentes níveis, etapas e modalidades da educação, os recursos educacionais podem representar espaço de criação, autonomia, pesquisa e, por que não dizer, de alegria quando idealizados, confeccionados, validados e aplicados pelos próprios licenciandos com apoio e orientação de seus professores formadores, das áreas específicas e pedagógicas? Quando se oferece liberdade para criar é possível que todos se sintam autores da própria prática, porque o são, e mais disponíveis para aprender e ensinar.

Nesse contexto, foram desenvolvidas oficinas de produção de recursos didáticos junto a licenciandos em Química do 5 o período do Ifes que cursaram a disciplina de Instrumentação para o Ensino de Ciências (IEC).

\section{CENÁRIO INSTITUCIONAL}

Em 2006 teve início o curso de licenciatura em Química no campus Vitória do Ifes. A matriz curricular original não trazia componente curricular de IEC que foi implantado a partir da revisão do Projeto Pedagógico do Curso (PPC) ocorrida em 2012, quando essa licenciatura havia sido transferida para 0 campus Vila Velha em período integral e novo curso de licenciatura em Química implantado, desde 2010, no campus Aracruz, no turno da noite. Essa alteração no PPC fundamentou-se em normativa interna da instituição apontando disciplinas básicas do núcleo comum para formação inicial de professores em todos os cursos de licenciatura. $\mathrm{Na}$ última revisão desses documentos, normativa e PPCs, realizada em 2018, a disciplina de IEC foi mantida na matriz das licenciaturas do Ifes havendo poucos ajustes no respectivo plano de ensino nas duas licenciaturas em Química.

Nesse contexto, em 2013, o componente curricular de IEC foi ministrado pela primeira vez no campus Aracruz contendo corpo teórico abordando: educação em espaços não formais; experimentação no ensino de Química/Ciências; movimento Ciência Tecnologia, Sociedade e Ambiente (CTSA); recursos didáticos no ensino de Química/Ciências; uso das tecnologias no ensino de Química/Ciências; ciência e arte e divulgação científica. $\mathrm{O}$ fato de ser a primeira oferta do componente curricular conferiu maior liberdade à docente no desenvolvimento de cada conteúdo.

À época, legislações pertinentes à formação de professores como a Resolução CNE/CP № 02/2002 que instituía a duração e a carga horária dos cursos de licenciatura e seu respectivo parecer CNE/CP 28/2001, traziam a prática como componente curricular (PCC). O Parecer CNE/CES no 15/2005, publicado como esclarecimento de dúvidas acerca das Resoluções CNE/CP 01 e 02/2002, afirma que:

[...] a prática como componente curricular é o conjunto de atividades formativas que proporcionam experiências de aplicação de conhecimentos ou de desenvolvimento de procedimentos próprios ao 
exercício da docência. Por meio destas atividades, são colocados em uso, no âmbito do ensino, os conhecimentos, as competências e as habilidades adquiridos nas diversas atividades formativas que compõem o currículo do curso. As atividades caracterizadas como prática como componente curricular podem ser desenvolvidas como núcleo ou como parte de disciplinas ou de outras atividades formativas.

Assim, com intuito de promover experiências que estivessem em sintonia com essa dimensão formativa foi idealizado no contexto da Licenciatura em Química do Ifes desenvolvimento de oficinas de produção de recursos didáticos para ensino de Química/Ciências dentro da disciplina de IEC ofertada no $5^{\circ}$ período do curso. Os licenciandos deveriam ter liberdade para conceber, desenvolver, validar e aplicar os recursos didáticos. Embora, as Resoluções CNE/CP 01 e 02/2002 não estejam em vigor, a atual Resolução CNE/CP 02/2015 e seu Parecer CNE/CP 02/2015 que instituem as Diretrizes Curriculares Nacionais para a formação inicial e continuada em nível superior de profissionais do magistério para a Educação Básica, seguem na mesma perspectiva de valorização das PCC.

Dessa forma, são descritas a seguir diferentes etapas vivenciadas no desenvolvimento das oficinas ao longo dos últimos sete anos.

\section{DAS OFICINAS}

De 2013 até 2019 ocorreram oito edições das oficinas de produção de recursos didáticos e, nesse ínterim, ajustes e aprimoramentos aconteceram a partir de avaliações da docente responsável pelo componente curricular de IEC e de sugestões dos licenciandos e de outros docentes formadores.

Em geral, cada oficina foi dividida em sete momentos (Figura 1): orientações iniciais acerca da atividade; aprofundamento teórico e planejamento do recurso didático; orientações extraclasse com docentes formadores; socialização de ideias e desafios na turma de IEC; desenvolvimento do recurso didático; validação do material - ocorrido oficialmente nas duas últimas edições - e apresentação do produto em diferentes momentos na disciplina e em eventos institucionais. 
Figura 1 - Momentos de cada oficina.

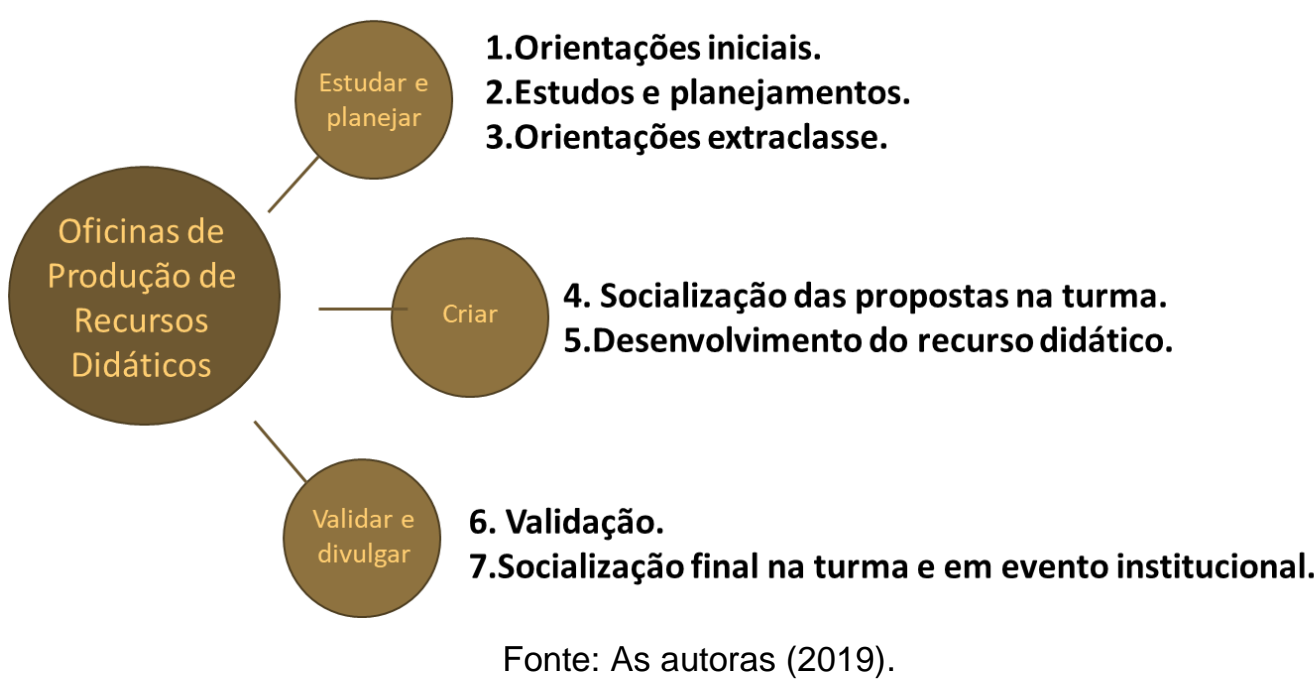

Nas cinco primeiras edições, ocorridas entre os anos de 2013 e 2016, a atividade foi apresentada aos licenciandos com, aproximadamente, dois meses de antecedência, logo após estudos acerca do tema: movimento CTSA. A partir de 2017 esse prazo foi paulatinamente estendido em função das ações realizadas na produção dos recursos didáticos. Em 2017/1 o prazo foi de 10 semanas, em 2018/1 de três meses e em 2019/1 foi de quatro meses. $\mathrm{Na}$ última oficina, a atividade foi apresentada no início do semestre e finalizada nos seus últimos dias letivos, totalizando $x$ meses. No que tange às atividades desenvolvidas, nas cinco primeiras oficinas não havia obrigatoriedade de testar ou validar o produto antes da apresentação final. Daí a necessidade de aumentar o prazo para execução da atividade a partir de 2017.

Em todas as edições das oficinas houve momento específico de duas aulas, previstas em calendário, antes da apresentação final, para que as duplas e trios de trabalho socializassem suas intenções em nível de tipo de material didático, conteúdo abordado, público alvo, juntamente com desafios até então enfrentados. Além desse momento os licenciandos também tiveram a possibilidade de agendar horários extras de orientação com a docente da disciplina e, posteriormente, nas edições de 2018 e 2019, também com docentes orientadores no campo dos saberes científicos.

No momento da apresentação da atividade aos licenciandos era socializado material digital de orientação contendo informações detalhadas acerca das oficinas, dentre essas: fundamentação teórica; passo a passo indicando o que fazer, quando fazer, como fazer, quem envolver e para que fazer; cronograma de execução e critérios de avaliação. Os critérios de avaliação nas diferentes edições estão apresentados no quadro 1.

Além de estimular aprendizados mais práticos acerca dos pressupostos do movimento CTSA era intuito das oficinas favorecer, na formação inicial dos estudantes, a pesquisa e as práticas de ensino que considerem as teorias de aprendizagem e questões conceituais da Química. Era ainda objetivo da atividade oportunizar ao licenciando experiências que favorecessem sua autonomia, sua autoria, sua criatividade, seu compromisso com a 
aprendizagem do futuro discente e sua capacidade de dialogar com diferentes saberes e diferentes públicos de docentes e estudantes.

As quatro primeiras edições das oficinas aconteceram nos anos de 2013, 2014 e 2015, no campus Aracruz do Ifes, e nesses momentos a proposta foi associar a temática de recursos didáticos para ensino de ciências com os princípios teóricos e filosóficos do movimento CTSA, conforme mostra o quadro 1. Válido ressaltar que a disciplina de IEC foi ofertada nos dois semestres de 2013 da licenciatura em Química do Campus Aracruz em função de ajustes na matriz curricular e da migração de discentes para a nova matriz. Assim, nessas oficinas, foi solicitado aos licenciandos em Química que deveriam, em duplas ou trios de trabalho, idealizar e desenvolver um recurso didático para ensinar Química para estudantes do Ensino Médio ou do nono ano do Ensino Fundamental. Contudo, esse recurso não deveria abordar questões meramente conceituais. Era necessário que os conteúdos fossem abordados dentro de contextos específicos que apontassem implicações ambientais, sociais, políticas, econômicas e/ou éticas da ciência. $\mathrm{O}$ objetivo de tal abordagem era que o discente da educação básica, ao interagir com o material, e o próprio licenciando ao desenvolvê-lo, tivesse a possibilidade de ampliar a formação para além das questões tidas como meramente conceituais.

Quadro 1: Modificações no material digital de orientação sobre as oficinas.

\begin{tabular}{|c|c|c|}
\hline $\begin{array}{c}\text { Período } \\
\text { da } \\
\text { oficina }\end{array}$ & $\begin{array}{c}\text { Conteúdo } \\
\text { abordado no } \\
\text { material }\end{array}$ & Critérios de avaliação proposta \\
\hline $\begin{array}{l}2013 \text { até } \\
2017\end{array}$ & Movimento CTSA & $\begin{array}{l}\text { Apresentação: } \\
\text { - quanto ao domínio dos conteúdos Químicos e } \\
\text { Pedagógicos; } \\
\text { - quanto à comunicação; } \\
\text { - quanto à criatividade e objetividade. } \\
\text { Recurso didático e estratégia de aplicação: } \\
\text { - adequação à faixa etária; } \\
\text { - ludicidade; } \\
\text { - conteúdo Químico e abordagem CTSA; } \\
\text { - conteúdo pedagógico. }\end{array}$ \\
\hline $\begin{array}{l}2018 \mathrm{e} \\
2019\end{array}$ & $\begin{array}{l}\text { Movimento CTSA } \\
\text { Inclusão escolar }\end{array}$ & $\begin{array}{l}\text { Apresentação: } \\
\text { - quanto ao domínio dos conteúdos Químicos e } \\
\text { Pedagógicos; } \\
\text { - quanto à comunicação; } \\
\text { - quanto à criatividade e objetividade. } \\
\text { Recurso didático e estratégia de aplicação: } \\
\text { - adequação à faixa etária; } \\
\text { - ludicidade; } \\
\text { - conteúdo Químico e abordagem CTSA; } \\
\text { - conteúdo pedagógico e inclusivo; } \\
\text { - validação. }\end{array}$ \\
\hline
\end{tabular}

Fonte: As autoras (2019) 
Nessas primeiras edições das oficinas (Quadro 2) dos 27 produtos gerados, 17 foram jogos educativos abordando temas variados da Química, três paródias, um modelo pedagógico, um quebra cabeça, uma proposta de gincana educativa, um painel eletrônico educativo, uma dinâmica de grupos envolvendo cruzadinhas, uma esquete teatral abordando o uso de drogas lícitas e ilícitas e um folder educativo abordando questões ambientais de conservação da água. Os momentos de apresentação foram ricos e divertidos. Além de todos interagirem com os recursos didáticos, também realizaram avaliação oral coletiva com registros realizados pelos componentes de cada grupo e pela docente. Embora essa avaliação oral dos discentes não implicasse diretamente na nota, era importante para avaliar se o material promoveria os aprendizados esperados, se estava em sintonia com pressupostos do movimento CTSA, se os conceitos de Química/Ciências abordados estavam corretos e se a estratégia de aplicação apresentava fundamentação pedagógica.

Quadro 2: Produtos oficinas de recursos didáticos em 2013, 2014 e 2015, campus Aracruz.

\begin{tabular}{|c|c|c|c|}
\hline $\begin{array}{c}\text { Período } \\
\text { da } \\
\text { Oficina }\end{array}$ & $\begin{array}{c}\text { Alunos } \\
\text { Aprovados }\end{array}$ & $\begin{array}{l}\text { Recursos } \\
\text { Gerados }\end{array}$ & Tipos de recursos \\
\hline $2013 / 1$ & 23 & 11 & $\begin{array}{l}\text { - } 7 \text { jogos: } 2 \text { de tabuleiro com perguntas e } \\
\text { respostas, } 2 \text { de cartas e } 3 \text { de cartas com } \\
\text { dinâmica abordando temas variados da } \\
\text { Química; } \\
\text { - } 1 \text { Paródia sobre a ciência Química; } \\
\text { - } 1 \text { Gincana educativa sobre reciclagem; } \\
-1 \text { Modelo de filtro caseiro feito com } \\
\text { cascalho, e garrafa PET; } \\
-1 \text { texto para esquete teatral sobre prevenção } \\
\text { ao uso de drogas lícitas e ilícitas. }\end{array}$ \\
\hline $2013 / 2$ & 13 & 7 & $\begin{array}{l}\text { - } 4 \text { jogos: } 1 \text { de tabuleiro, } 1 \text { de dardo com a } \\
\text { tabela periódica, } 1 \text { de tabuleiro e cartas e } 1 \\
\text { jogo de cartas abordando temas variados da } \\
\text { Química; } \\
\text { - } 1 \text { dinâmica de grupo: cruzadinha abordando } \\
\text { temas variados da Química; } \\
-1 \text { quebra cabeça da Tabela Periódica } \\
\text { seguido de jogo com um dado gigante; } \\
-1 \text { painel eletrônico educativo abordando } \\
\text { grupos funcionais de Química Orgânica. }\end{array}$ \\
\hline $2014 / 2$ & 11 & 5 & $\begin{array}{l}\text { - } 4 \text { jogos: } 1 \text { de tabuleiro com cartas, } 2 \text { de } \\
\text { cartas envolvendo perguntas e respostas e } 1 \\
\text { de perguntas e respostas abordando temas } \\
\text { gerais da Química; } \\
-1 \text { paródia. }\end{array}$ \\
\hline $2015 / 2$ & 9 & 4 & $\begin{array}{l}\text { - } 2 \text { jogos; } 1 \text { de bingo e } 1 \text { de tabuleiro } \\
\text { abordando temas gerais da Química; } \\
-1 \text { vídeo / paródia abordando questões } \\
\text { ambientais; } \\
-1 \text { folder educativo abordando questões } \\
\text { ambientais. }\end{array}$ \\
\hline
\end{tabular}

Fonte: As autoras (2019). 
A partir dessas primeiras edições foi possível avaliar a ação pedagógica e pensar em ajustes no desenvolvimento das oficinas para semestres posteriores. A abordagem CTSA, quando contemplada, se restringia a questões ambientais, não havendo associação intencional às implicações sociais, políticas, econômicas, éticas e estéticas, embora existissem possibilidades para tal. Alguns materiais também apresentaram erros conceituais de Química, em geral, detectados pela docente durante apresentações finais. Esses erros envolviam falha nas respostas esperadas quanto aos conteúdos químicos, respostas esperadas com dupla interpretação e, em menor número, questões apresentadas de maneira equivocada ou dúbia. Nesse viés, ressalta-se que, quando os licenciandos procuravam orientações com a docente da disciplina para apresentar prévia do recurso didático, já com os temas químicos contemplados, era possível identificar alguns desses erros com antecedência e corrigi-los. Contudo, na maioria dos momentos de orientação os temas abordados envolviam fases iniciais do desenvolvimento do recurso didático. Habitualmente, tratava-se do tipo de recurso a ser desenvolvido, do público alvo e das estratégias de aplicação e confecção dos recursos, levando em conta materiais e custos.

Para as quatro edições seguintes das oficinas, nos anos de 2016, 2017, 2018 e 2019 foi solicitado que os licenciandos buscassem apoio de um docente da área específica da Química a fim de orientarem as questões conceituais, no intuito de evitar erros e, também, no apontamento de possíveis implicações sociais, políticas e econômicas do conteúdo abordado. Inicialmente, a busca do apoio teórico em química, ficou como responsabilidade do próprio licenciando.

Ao longo do segundo semestre do ano de 2016 a docente da disciplina passou por remoção entre dois campi do Ifes e não foi possível finalizar a atividade das oficinas com esse grupo de alunos. No campus Vila Velha as oficinas foram realizadas dentro da mesma disciplina de IEC, também ofertada no quinto período do curso. No que tange à oficina realizada no ano de 2017, foi possível perceber avanço quanto à redução dos erros conceituais de Química nos produtos gerados. Contudo, ainda se faziam presentes. Quanto à abordagem CTSA houve melhora na forma que alguns grupos contemplaram os conteúdos partindo de temas de relevância social para abordar o conteúdo Químico. Dos 12 recursos didáticos produzidos pelos licenciandos desta turma (Quadro 3), quatro realizaram abordagem CTSA de maneira fundamentada. Contudo, os outros oito mantiveram perfil semelhante ao das oficinas anteriores, ou seja, ou não aparecia a abordagem CTSA ou era de cunho meramente ambiental sem destaque para demais implicações. Válido ressaltar que a receptividade pelas oficinas por parte dos licenciandos do novo campus foi muito boa, com posturas de curiosidade e pró atividade.

Para a edição de 2018, com intuito de aprimorar ainda mais as oficinas, foi realizado contato prévio com docentes formadores de áreas específicas das Ciências Naturais do campus Vila Velha do Ifes a fim de verificar interesse em contribuir com a orientação de grupo de licenciandos. Como nas edições anteriores essa indicação ocorreu em nível de sugestão, não havendo obrigatoriedade, julgou-se importante agora fazê-lo de forma direta para que esses docentes também se sentissem autores e parte do processo. Assim, a 
docente da disciplina de IEC realizou reunião prévia esclarecendo objetivos e metodologias com cada docente que aceitou o convite para participar da atividade, socializando material digital de orientação. Quando os licenciandos receberam esse material digital, já constava quadro com indicação de 17 docentes vinculados e suas áreas específicas de interesse para orientação. Apenas uma docente convidada não se juntou à atividade em função do acúmulo de tarefas, mas afirmou desejar participar futuramente, fato que se concretizou na edição seguinte das oficinas. Ainda que não fosse objetivo inicial da atividade, criou-se possibilidade de contribuir para formação continuada de outros professores formadores em nível de atuação pedagógica, novas metodologias de ensino e recursos didáticos.

Outra inovação para as oficinas de 2018 foi a produção de recursos didáticos inclusivos para ensinar ciências a pessoas com deficiências. A sugestão partiu do Pedagogo do campus Vila Velha. Assim, em 2018, os alunos foram desafiados a desenvolver recursos didáticos inclusivos, para ensinar Química à luz dos pressupostos do movimento CTSA. A realização de uma etapa de validação do material também foi novo item inserido nos critérios de avaliação.

Como resultado (Quadro 3) foram gerados 10 recursos dos quais seis foram modelos didáticos, duas histórias em quadrinhos, uma em Braille e outra em áudio descrição, uma cozinha sensorial e uma oficina de produção de sabão traduzida em Libras. Todos apresentaram envolvimento com o tema da inclusão, seis abordaram questões conceituais da Química sem a perspectiva CTSA e os outros quatro apresentaram abordagem conceitual associada aos pressupostos do movimento CTSA com forte potencial para abordagem de questões políticas, sociais, econômicas e ambientais, mas ainda pouco exploradas.

Todavia, alguns recursos, mais especificamente três, ainda apresentaram erros conceituais. Um dos professores orientadores atribuiu esses erros ao fato de os licenciandos desses grupos não se comprometerem com os momentos de orientação em nível de quantidade de encontros e de aprofundamento teórico. Esse mesmo docente sugeriu que para edições futuras das oficinas, fossem indicadas quantidades mínimas de reuniões de orientação com registro em formulário próprio. Sugeriu ainda que o licenciando só deveria poder apresentar o recurso didático se o professor orientador autorizasse. Todas essas sugestões foram postas em prática na edição de 2019.

Ao final do primeiro semestre de 2018 ocorreu no campus Vila Velha a III Jornada Integrada de Educação em Ciências, quando houve momento específico em que os licenciandos puderam expor e avaliar os materiais produzidos a partir da análise direta de pessoas público alvo dos recursos didáticos, dentre eles, deficientes visuais e auditivos, que compareceram ao evento a convite da instituição. Esse foi momento de muitas trocas e aprendizados, quando surgiram sugestões de aprimoramento e ajustes em alguns dos recursos a partir da percepção dos próprios visitantes.

Nas oficinas de 2019, conforme sugestão de docente orientador no ano anterior, foram mantidas as orientações com professores especialistas nas 
áreas de Química/Ciências, os momentos de orientação foram registrados em formulário próprio e o discente só pôde apresentar o trabalho final mediante autorização de seu orientador. Nessa nova edição os discentes foram convidados a desenvolver recursos didáticos que poderiam ser inclusivos ou não. Metade dos grupos produziu recurso inclusivo e a outra metade não. Essa escolha foi feita com sorteio, pois a maioria não desejava desenvolver recursos inclusivos por julgarem apresentar maior grau de dificuldades. Conforme descrito no Quadro 3, nessa edição foram criados oito recursos didáticos, sendo sete jogos e um modelo molecular.

Embora existisse, nas edições de 2017, 2018 e 2019, a possibilidade de desenvolver recursos didáticos para estudantes da educação básica e superior, apenas um dos recursos desenvolvido em 2018, foi pensado para a educação superior, todos os demais foram pensados para a educação básica.

Quadro 3: Produtos oficinas de recursos didáticos em 2017, 2018 e 2019, campus Vila Velha.

\begin{tabular}{|c|c|c|c|}
\hline $\begin{array}{l}\text { Período da } \\
\text { Oficina }\end{array}$ & $\begin{array}{c}\text { Alunos } \\
\text { Aprovados }\end{array}$ & $\begin{array}{c}\text { Recursos } \\
\text { Gerados }\end{array}$ & Tipos de recursos \\
\hline $2017 / 1$ & 23 & 12 & $\begin{array}{l}\text { - } 11 \text { jogos: } 4 \text { de tabuleiro e } \\
\text { cartas, } 5 \text { de cartas, } 1 \text { quiz } \\
\text { eletrônico e } 1 \text { de tabela } \\
\text { periódica com cartas abordando } \\
\text { temas variados de Química; } \\
-1 \text { Sequência Didática } \\
\text { abordando tema de resíduos } \\
\text { sólidos. }\end{array}$ \\
\hline $2018 / 1$ & 24 & 10 & $\begin{array}{l}\text { - } 6 \text { modelos: atômicos, } \\
\text { moleculares, de balança, de } \\
\text { filtro, de tabela periódica; } \\
\text { - } 2 \text { HQs: em Braile abordando } \\
\text { reciclagem e em áudio } \\
\text { descrição abordando Química } \\
\text { forense; } \\
-1 \text { Cozinha sensorial } \\
\text { abordando conteúdos de } \\
\text { Química Geral; } \\
-1 \text { Oficina de produção de } \\
\text { sabão traduzida em Libras. }\end{array}$ \\
\hline 2019/1 & 15 & 08 & $\begin{array}{l}\text { - } 7 \text { jogos: } 1 \text { de tabuleiro e } \\
\text { questões apresentadas com } \\
\text { data show, } 1 \text { de equipe } \\
\text { simulando Imagem \& Ação, } 2 \\
\text { com modelos atômico e } \\
\text { moleculares para serem } \\
\text { montados e - } 3 \text { jogos de cartas. } \\
\text { - } 1 \text { Modelo molecular. }\end{array}$ \\
\hline
\end{tabular}

Fonte: As autoras (2019).

No quadro 4 estão sintetizados os recursos produzidos em todas as oficinas, somando um total de 57 recursos (Quadro 4), dos quais 35 são jogos educativos. 
Quadro 4: Tipo e quantidade de recursos produzidos em todas as edições das oficinas.

\begin{tabular}{|c|c|}
\hline Tipo de Recurso Didático & Quantidade \\
\hline Jogos educativos & 35 \\
\hline Modelos atômicos ou moleculares & 08 \\
\hline Dinâmicas de grupo & 04 \\
\hline Paródias & 03 \\
\hline Histórias em Quadrinhos & 02 \\
\hline Sequência didática & 01 \\
\hline Folder educativo & 01 \\
\hline Quebra cabeça & 01 \\
\hline Painel eletrônico & 01 \\
\hline Texto para esquete teatral & 01 \\
\hline Total & $\mathbf{5 7}$ \\
\hline
\end{tabular}

Fonte: As autoras (2019).

\section{REFLETINDO COM AS EXPERIÊNCIAS}

Ao analisar possíveis alcances dessas oficinas na formação inicial dos docentes de química é válido retomar com Nóvoa (1999) breve percurso histórico em que, a partir da década noventa do século passado, reforçaram-se processos de exclusão dos professores fazendo repensar seus papeis profissionais. Para esclarecer esses processos Nóvoa (1999) se vale da metáfora do jogo de cartas de bridge em que "[...] um dos parceiros ocupa 0 'lugar do morto', sendo obrigado a expor as suas cartas em cima da mesa: nenhuma jogada pode ser feita sem atender às suas cartas, mas este não pode interferir no desenrolar do jogo" (p. 7). Assim, idealiza um triângulo do conhecimento de maneira que cada vértice traduza a existência de três grandes tipos de saberes: o saber da experiência (professores); o saber da pedagogia (especialistas em ciências da educação) e o saber das disciplinas (especialistas dos diferentes domínios do conhecimento).

Figura 2 - Triângulo do conhecimento.

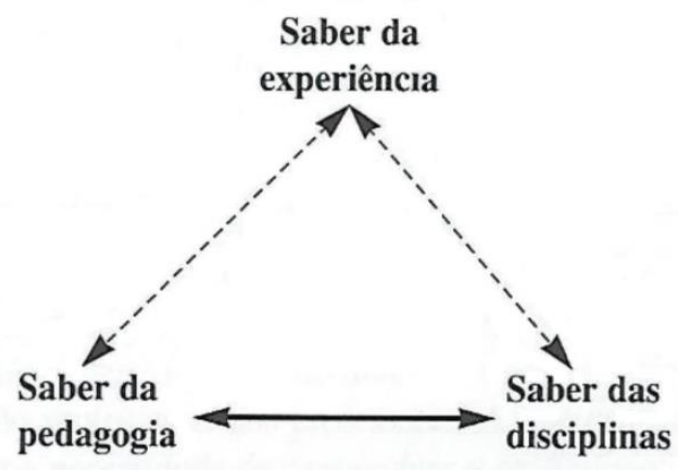

Fonte: Nóvoa (1999, p.9). 
Ao esclarecer o que pretende representar com a figura, Nóvoa (1999) afirma que:

\begin{abstract}
Nos períodos de inovação educacional há uma certa tendência para valorizar a ligação dos professores aos especialistas pedagógicos. Nos momentos mais conservadores procura-se juntar o saber da experiência ao saber das disciplinas. Actualmente, o saber dos professores tende a ser desvalorizado em favor de um saber científico (da pedagogia ou das outras disciplinas) (p. 9).
\end{abstract}

Aponta ainda paradoxo na história dos professores que reside no fato de "[...] os tempos-fortes da reflexão científica em educação contribuírem para um maior prestígio social da profissão, mas também, e simultaneamente, para uma desvalorização dos seus saberes próprios" (NÓVOA, 1999, p. 9). Para ele, as práticas de racionalização do ensino contêm os elementos de uma deslegitimação dos professores como produtores de saber, práticas essas que as oficinas de produção de recursos didáticos aqui descritas buscam descontruir

Notadamente, ao longo da vivência das oficinas, houve articulação entre saberes pedagógicos, específicos e da experiência (NÓVOA, 1999). Para desenvolver, testar e aplicar cada recurso didático, licenciandos e docentes orientadores necessitaram envolver saberes específicos de Química/Ciências, avaliar a capacidade de o recurso mediar construção de saberes e ainda, ao utilizá-lo no dia a dia da sala de aula, perceber contextos que se revelam apenas na prática. As oficinas também favoreceram interlocução entre docentes formadores de diferentes áreas de conhecimento fato perceptível quando docentes de áreas específicas e pedagógicas se procuravam no sentido de juntos, buscarem meios para mediar construção de saberes em nível de correção conceitual, adequação pedagógica para cada faixa etária e, quando desejado, envolvendo ludicidade. Outra interlocução potencializada a partir das oficinas de recursos didáticos foi a parceria que o campus Vila Velha do Ifes realizou com uma instituição privada de ensino superior que oferece curso de Ciências da Computação em função de um dos jogos produzidos nas oficinas. Tal jogo está em fase de desenvolvimento para dispositivos móveis a partir do trabalho de conclusão de curso de uma dupla de discentes do referido curso.

Os momentos de apresentação foram de diversão e leveza, havendo interação dos estudantes com os recursos didáticos, quando todos podiam avaliá-los quanto às questões conceituais e objetivos, quanto à ludicidade e ao tipo de interação que promoviam. Algumas vezes o recurso inicialmente idealizado para uma função, durante o desenvolvimento e apresentações, revelava outras potencialidades. A partir da edição de 2018, quando as orientações com docentes especialistas passaram a acontecer de maneira sistematizada, esses docentes eram sempre convidados a participar das apresentações dos produtos em aula e, também, nos eventos internos no lfes. De maneira geral, eles compareciam com maior frequência nos eventos institucionais.

Entendendo a Prática como Componente Curricular como conjunto de 
"[...] experiências de aplicação de conhecimentos ou de desenvolvimento de procedimentos próprios ao exercício da docência [...]" (BRASIL, 2005), compreende-se que as oficinas favorecem tal dimensão formativa do docente por meio das inevitáveis interlocuções entre os diferentes saberes pedagógicos, específicos e da experiência, que os discentes têm que realizar para desenvolver o recurso. É preciso domínio da Química e conhecimento pedagógico das possibilidades de interação entre estudante, recurso didático e construção de novos saberes. O diálogo com os saberes da experiência (NÓVOA, 1999), ainda que o licenciando não o perceba de imediato, acontece e é papel do professor formador Ihes dar visibilidade. Um exemplo desse contexto diz respeito à realização de atividades em que a interação com 0 recurso didático gera barulho e certa agitação dos discentes. Nesse contexto, é comum o licenciando demonstrar insegurança em não conseguir manter a ordem na turma, de não conseguir manejar com segurança a relação entre autoridade e liberdade. Entra aí o papel do professor formador na orientação de como conduzir esses momentos e como orientar seus licenciandos nessa condução, sem perder a ludicidade. Nesse sentido, Paulo Freire na primeira carta pedagógica publicada no livro Pedagogia da Indignação (2000) afirma estar convencido de que:

\begin{abstract}
[...] nenhuma educação que pretenda estar a serviço da boniteza da presença humana no mundo, a serviço da seriedade da rigorosidade ética, da justiça, da firmeza do caráter, do respeito às diferenças, engajada na luta pela realização do sonho da solidariedade pode realizar-se ausente da tensa e dramática relação entre autoridade e liberdade. Tensa e dramática relação em que ambas, autoridade e liberdade, vivendo plenamente seus limites e suas possibilidades, aprendem, sem tréguas, quase, a assumir-se como autoridade e como liberdade. É vivendo com lucidez a tensa relação entre autoridade e liberdade que ambas descobrem não serem necessariamente antagônicas uma da outra (p. 18).
\end{abstract}

Outro exemplo de diálogo entre diferentes saberes que legitima o professor como produtor de seu saber e que reflete teoria e prática na vivência da própria experiência diz respeito ao contato entre professores formadores de áreas específicas e pedagógicas. Uma das professoras, a partir das orientações nas oficinas, submeteu projeto de iniciação científica para orientar desenvolvimento de recurso didático para suas disciplinas de conhecimentos específicos. É nesse contexto:

[...] que a dialogicidade verdadeira, em que os sujeitos dialógicos aprendem e crescem na diferença, sobretudo, no respeito a ela, é a forma de estar sendo coerentemente exigida por seres que, inacabados, assumindo-se como tais, se tornam radicalmente éticos (FREIRE, 1996, p. 35).

Aspecto a ser também valorizado é o quanto as oficinas conferem aos licenciandos liberdade para criar, autonomia para agir e o quanto dão a eles 0 sentimento de autoria, novamente, de produtores de saberes. Em nenhuma 
das oficinas foi determinado o recurso didático que deveria ser desenvolvido ou - conteúdo a ser abordado ou o público alvo específico. Alguns direcionamentos foram oferecidos, mas a escolha do que fazer, como fazer, para quem fazer, o que abordar e como abordar, foram decisões dos licenciandos e, posteriormente, deles com seus orientadores. Nesse viés, Freire (1996, p. 140-141) aponta que:

\begin{abstract}
Todo ensino de conteúdos demanda de quem se acha na posição de aprendiz que, a partir de certo momento, vá assumindo a autoria também do conhecimento do objeto. [...] É por isso que o ensino dos conteúdos, criticamente realizado, envolve a abertura total do professor ou da professora, à tentativa legítima do educando para tomar em suas mãos a responsabilidade de sujeito que conhece. Mais ainda, envolve a iniciativa do professor que deve estimular aquela tentativa no educando, ajudando-o para que a efetive.
\end{abstract}

Válido destacar apresentação de comunicação oral realizada por uma dupla de licenciandas a partir de produto gerado na primeira edição das oficinas em 2013/1 no XVIII Encontro Nacional de Ensino de Química realizado em 2016. A participação em eventos científicos representa etapa formativa relevante na constituição de intelectuais reflexivos (PIMENTA, 2002) e pesquisadores de sua prática (ESTEBAN e ZACCUR, 2002).

Outro aspecto relevante a ser destacado foi a criação, a partir de 2018/1, da Mostra de Recursos Didáticos do campus Vila Velha do Ifes para dar visibilidade aos produtos gerados pelos licenciandos. Nesse momento é realizado convite à comunidade externa e interna e os licenciandos apresentam o produto que desenvolveram com seus fundamentos científicos pedagógicos, incentivando o público a interagir com 0 recurso didático. Mais uma oportunidade de formação autônoma para os licenciandos.

No que diz respeito aos desafios, para além da promoção de uma formação de professores mais sintonizada com a práxis que deles se espera, a expectativa era de criar acervo de recursos a serem utilizados na formação inicial e na educação básica por meio dos estágios supervisionados, do Programa Institucional de Iniciação à Docência (PIBID) e, atualmente, da Residência Pedagógica. Contudo, em todas as edições das oficinas houve identificação de erros conceituais nos recursos o que demandou mais tempo para correção. Grande parte dos recursos foi corrigido e, somente depois, puderam ser utilizados nas escolas de educação básica. Alguns não foram corrigidos e, por consequência, não puderam ser reutilizados. Esses erros foram diminuindo a cada nova edição, a partir da parceria com os docentes das áreas específicas. Quanto ao armazenamento e empréstimo dos recursos, atualmente ficam guardados no Laboratório de Ensino ou na sala da professora da disciplina de IEC e o controle é feito de forma amadora sem que haja registro formal de retirada e devolução, ações essas a serem ajustadas. Válido destacar que esses recursos são recorrentemente utilizados pelos licenciandos que atuam no PIBID, na residência Pedagógica, nos estágios supervisionados e, mesmo alunos que já se graduaram, retornam ao campus para solicitar empréstimo dos materiais que já conheciam. 
Outro aspecto a ser aprimorado diz respeito à abordagem CTSA. Neste caso, ou o recurso não apresentava essa perspectiva ou era negligenciada durante aplicação do material. Recursos didáticos que abordam conteúdos a partir de perspectiva CTSA devem ter caráter multidisciplinar evidenciando diferentes dimensões dos conhecimentos estudados, sobretudo as interações entre ciência, tecnologia, sociedade e ambiente (SANTOS e MORTIMER, 2002). Assim:

[...] A proposta curricular de CTS corresponderia, portanto, a uma integração entre educação científica, tecnológica e social, em que os conteúdos científicos e tecnológicos são estudados juntamente com a discussão de seus aspectos históricos, éticos, políticos e sócioeconômicos (LÓPEZ e CEREZO, 1996).

Abordar conteúdos científicos a partir de aspectos políticos e sócio econômicos não é fácil. Em geral, não se oferece formação pautada nesses princípios, decorrendo daí grandes desafios, mas também elevadas possibilidades de inovação. Levar o licenciando e o professor formador a perceberem essa dimensão também lhes dá o sentido da possibilidade de autoria.

No que diz respeito aos recursos desenvolvidos na perspectiva inclusiva, sabe-se que o "atendimento educacional especializado aos portadores de deficiência, preferencialmente na rede regular de ensino" (BRASIL, 1988) é princípio constitucional e que, para garantir tal atendimento, é necessário que professores tenham formação adequada. Contudo, em consonância com Moreira (2007), entende-se que a formação inicial de professores para a educação básica apresenta significativas lacunas nesse aspecto. É preciso buscar garantir:

[...] uma formação que viva a inclusão e ultrapasse a linearidade e a simplificação curricular de que basta uma disciplina sobre a área da NEE (Necessidades Educativas Especiais) para formar professores capacitados a atuarem com o alunado que apresenta necessidades mais especiais (p. 268).

Nesse contexto, avalia-se que as oficinas de produção de recursos didáticos com direcionamento para o desenvolvimento de recursos inclusivos, têm muito a contribuir na formação inicial de professores de Química em função de abordar a temática não só no campo teórico, mas na dimensão prática e pedagógica.

Para além desses desafios, são elevadas as perspectivas de aprimoramento das oficinas no sentido de criar momentos que, de fato, favoreçam ainda mais a dimensão das PCC e a formação do professor crítico reflexivo e pesquisador da própria prática. 


\section{CONSIDERAÇÕES FINAIS}

Desde a formação inicial é fundamental que o docente aprenda a ser protagonista da própria ação pedagógica e as oficinas de recursos didáticos têm se mostrado ferramentas potencializadoras desse protagonismo e, por consequência, de valor inestimável no compromisso que esse educador poderá assumir no estímulo ao protagonismo de seus futuros discentes. Assim, são postas condições favoráveis para a superação de uma alienação técnica em favor de uma autonomia crítica por parte daquele que se nomeia, de fato, professor pesquisador (PIMENTA, 2002). E ainda, os cursos de licenciatura se apresentam como espaços que, além de oferecer conhecimentos teóricos, também são capazes de articular a prática com a teoria que se ensina durante a formação universitária do futuro docente (SOUZA e BORGES, 2016).

Oportunizar aos licenciandos experiências em que façam dialogar saberes específicos, pedagógicos e da experiência (NÓVOA, 1999), levandoos a perceber que seus professores formadores estão também comunicando diferentes saberes em prol da construção coletiva de novos conhecimentos, representa estímulo à interdisciplinaridade, mas, especialmente, incentivo à valorização das dimensões: ética, estética e política da educação. Ética quando se educa para a autonomia e emancipação, estética quando se educa para a sensibilidade e criatividade e política quando se educa para uma cidadania ativa. Esses são fundamentos axiológicos na formação do ser humano (ARANHA, 2006).

Para tanto, as práticas como componente curricular, propostas desde 2002 em documentos oficiais que disciplinam a formação de professores no Brasil, podem se configurar como espaços de autonomia, autoria, criatividade e liberdade para licenciandos e seus formadores. Pelo caráter ainda não claramente compreendido, favorecem tentativas de inovação, que embora representem riscos, também indicam possibilidades de tentar, de errar, de acertar, de pesquisar, de aprender e de ensinar. Não é possível avançar sem correr riscos e é preciso que licenciandos se apropriem dessa realidade de maneira prática, compromissada, corajosa e lúcida, desde a formação inicial.

Daí a importância de uma educação que, em lugar de procurar negar o risco, estimule mulheres e homens a assumi-lo. É assumindo o risco, sua inevitabilidade, que me preparo ou me torno apto a assumir este risco que me desafia agora e a que devo responder. É fundamental que eu saiba não haver existência humana sem risco, de maior ou de menor perigo. Enquanto objetividade o risco implica a subjetividade de quem o corre. Neste sentido é que, primeiro, devo saber que a condição de existentes nos submete a riscos; segundo, devo lucidamente ir conhecendo e reconhecendo o risco que corro ou que posso vir a correr para poder conseguir um eficaz desempenho na minha relação com ele (FREIRE, 2000, p.16).

Entende-se, portanto, que as oficinas de produção de recursos didáticos, para além de favorecerem a formação técnica, científica e pedagógica dos licenciandos, contribuem para sua formação em valores quando aprendem a 
conhecer, respeitar e valorizar necessidades de aprendizagem de seus educandos. Favorecem aprendizagens na dimensão prática que, pelo próprio caráter empírico, não podem se dar somente na teoria - nem dela dissociada entre paredes de uma sala de aula, mas conectadas a contextos reais. Oportunizam diálogo entre diferentes saberes quando o licenciando compreende que não basta dominar somente o conteúdo específico, menos ainda dominar unicamente a forma de ensiná-lo. É preciso que esses saberes dialoguem na prática. Sem esse diálogo a relação entre ensinar e aprender fica comprometida.

Oportunizar essas percepções, vivências e aprendizagens aos licenciandos desde o início de sua formação pode potencializar novos modos de ensinar e de aprender. Pode transformar o cenário educacional de maneira que licenciandos e formadores se sintam investidos "do direito e do dever de mudar o mundo" (FREIRE, 2000).

\section{REFERÊNCIAS}

ARANHA, M. L. A. Filosofia da educação. 3. ed. São Paulo: Moderna, 2006.

BRASIL. Casa Civil. Constituição da República Federativa do Brasil de $1988 . \quad$ Brasília, $1988 . \quad$ Disponível em: $<$ http://www.planalto.gov.br/ccivil 03/constituicao/constituicao.htm>. Acesso em: 02 ago. 2019.

BRASIL. Casa Civil. Lei de Diretrizes e Bases da Educação Nacional. Lei no 9.394/96, de 20 de dezembro de 1996. Brasília, 1996. Disponível em: $<$ http://www.planalto.gov.br/ccivil 03/Leis/L9394.htm>. Acesso em: 02 ago. 2019.

BRASIL. Conselho Nacional de Educação. Câmera de Educação Superior. Parecer CNE/CP 28, de 2 de outubro de 2001. Dá nova redação ao Parecer CNE/CP 21/2001, que estabelece a duração e a carga horária dos cursos de Formação de Professores da Educação Básica, em nível superior, curso de licenciatura, de graduação plena. Brasília, 2001. Disponível em: $<$ http://portal.mec.gov.br/cne/arquivos/pdf/028.pdf>. Acesso em: 15 jun. 2018.

BRASIL. Conselho Nacional de Educação. Conselho Pleno. Resolução CNE/CP 01, de 18 de fevereiro de 2002. Institui as Diretrizes Curriculares Nacionais para a Formação de Professores da Educação Básica, em nível superior, curso de licenciatura, de graduação plena. Brasília, 2002. Disponível em: < http://portal.mec.gov.br/seesp/arquivos/pdf/res1 2.pdf>. Acesso em: 02 jun. 2018.

BRASIL. Conselho Nacional de Educação. Conselho Pleno. Resolução CNE/CP 02, de 19 de fevereiro de 2002. Institui a duração e a carga horária dos cursos de licenciatura, de graduação plena, de formação de professores da Educação Básica em nível superior. Brasília, 2002. Disponível em: $<$ http://portal.mec.gov.br/cne/arquivos/pdf/CP022002.pdf> . Acesso em: 02 jun. 
2018.

BRASIL. Conselho Nacional de Educação. Câmera de Educação Superior. Parecer CNE/CES 15, de 2 de fevereiro de 2005. Solicitação de esclarecimento sobre as Resoluções CNE/CP ns 1/2002 e 2/2002, que instituem Diretrizes Curriculares Nacionais e duração e a carga horária dos cursos de licenciatura, de graduação plena, de Formação de Professores da Educação Básica, em nível superior. Brasília, 2005. Disponível em: < http://portal.mec.gov.br/cne/arquivos/pdf/pces0015 05.pdf>. Acesso em: 15 jun. 2018.

BRASIL. Conselho Nacional de Educação. Conselho Pleno. Parecer CNE/CP 02, de 9 de junho de 2015. Diretrizes Curriculares Nacionais para a formação inicial em nível superior (cursos de licenciatura, cursos de formação pedagógica para graduados e cursos de segunda licenciatura) e para a formação continuada. Brasília, 2015a. Disponível em: < http://portal.mec.gov.br/index.php?option=com docman\&view=download\&alias =17625-parecer-cne-cp-2-2015-aprovado-9-junho-2015\&Itemid=30192>.

Acesso em: 15 jun. 2018.

BRASIL. Conselho Nacional de Educação. Conselho Pleno. Resolução CNE/CP 02, de 1ำ de julho de 2015. Define as Diretrizes Curriculares Nacionais para a formação inicial em nível superior (cursos de licenciatura, cursos de formação pedagógica para graduados e cursos de segunda licenciatura) e para a formação continuada. Brasília, 2015b. Disponível em:<http://portal.mec.gov.br/index.php?option=com docman\&view=download\& alias=70431-res-cne-cp-002-03072015-pdf\&category slug=agosto-2017pdf\&Itemid=30192>. Acesso em: 02 jun. 2018.

DEMO, P. Educar Pela Pesquisa. 10.ed. Campinas, SP: Autores Associados, 2015.

ESTEBAN, M. T.; ZACCUR, E. A pesquisa como eixo de formação docente. In: ESTEBAN, Maria Teresa; ZACCUR, Edwiges (Orgs.). Professorapesquisadora: uma práxis em construção. Rio de Janeiro: DP\&A, 2002.

FREIRE, P. Pedagogia da Autonomia: saberes necessários à prática educativa. São Paulo: Paz e Terra, 1996.

FREIRE, P. Pedagogia da indignação: cartas pedagógicas e outros escritos. São Paulo: Editora Unesp, 2000.

LOPES, A C. Políticas de Currículo: mediação por grupos disciplinares de ensino de Ciências e Matemática. In: LOPES, A. C; MACEDO, E. (Orgs). Currículo de Ciências em Debate. Campinas: Papirus, 2004.

LÓPEZ, J. L. L., CEREZO, J. A. L. Educación CTS en acción: enseñanza secundaria y universidad. In: GARCÍA, M. I. G., CEREZO, J. A. L., LÓPEZ, J. L. L. Ciencia, tecnología y sociedad: una introducción al estudio social de la ciencia y la tecnología. Madrid: Editorial Tecnos S. A., 1996. 
MOREIRA, L. M. Cursos de licenciatura com bases inclusivas: impressões de alunos com necessidades especiais e seus professores. In: JESUS, Denise Meireles de, BAPTISTA, Cláudio Roberto, et al (org). Inclusão, práticas pedagógicas e trajetórias de pesquisa. Porto Alegre: Mediação / Prefeitura Municipal de Vitória, 2007.

NÓVOA, A. Profissão Professor. 2. ed. Lisboa: Porto Editora, 1999.

PIMENTA, S. G. Professor Reflexivo: construindo uma crítica. In: PIMENTA, Selma Garrido; GHEDIN, Evandro. Professor Reflexivo no Brasil: gênese e crítica de um conceito. São Paulo: Cortez, 2002.

SANTOS, W. L. P. dos; MORTIMER, E. F. Uma análise de pressupostos teóricos da abordagem C-T-S (Ciência - Tecnologia - Sociedade) no contexto da educação brasileira. Ensaio: Pesquisa em Educação em Ciências. Belo Horizonte, v. 2, n. 2, p. 1-23, dez. 2002.

SILVA, A. L; COMARÚ, M. W. A Pesquisa em Ensino de Ciências é Feita Por e Para Professores. In: COMARÚ, M. W; KAUARK, F. da S. (Orgs.). Ensinando a ensinar ciências: reflexões para docentes em formação. Vitória, ES: Edifes, 2017.

SOUZA, F. C. S.; BORGES, A. A. Estágio supervisionado e prática reflexiva: narrativas de concluintes da licenciatura em matemática (IFRN/Mossoró). RBEPT, n. 10, v. 1, p. 44-54. 2016. 